\title{
Insecticidal Activity of Essential Oil of Carum Carvi Fruits from China and Its Main Components against Two Grain Storage Insects
}

Rui Fang ${ }^{1}$, Cai Hong Jiang ${ }^{2}$, Xiu Yi Wang ${ }^{3}$, Hai Ming Zhang ${ }^{1}$, Zhi Long Liu ${ }^{2, *}$, Ligang Zhou ${ }^{4}$, Shu Shan Du ${ }^{1, *}$ and Zhi Wei Deng ${ }^{3}$

1 Protection and Utilization of Traditional Chinese Medicine of Beijing Area Major Laboratory, Beijing Normal University, Haidian District, Beijing 100875, China

2 Department of Entomology, China Agricultural University, Haidian District, Beijing 100094, China

3 Analytical and Testing Center, Beijing Normal University, Haidian District, Beijing 100875, China

4 Department of Plant Pathology, China Agricultural University, Haidian District, Beijing 100094, China

* Authors to whom correspondence should be addressed; E-Mail: zhilongliu@cau.edu.cn (Z.L.L.); dushushan@bnu.edu.cn (S.S.D.); Tel./Fax: +86-10-62732800; +86-10-62208032.

Received: 23 November 2010; in revised form: 10 December 2010 / Accepted: 17 December 2010 / Published: 20 December 2010

\begin{abstract}
During our screening program for agrochemicals from Chinese medicinal herbs and wild plants, the essential oil of Carum carvi fruits was found to possess strong contact toxicity against Sitophilus zeamais and Tribolium castaneum adults, with $\mathrm{LD}_{50}$ values of 3.07 and $3.29 \mu \mathrm{g} / \mathrm{adult}$, respectively, and also showed strong fumigant toxicity against the two grain storage insects with $\mathrm{LC}_{50}$ values of 3.37 and $2.53 \mathrm{mg} / \mathrm{L}$, respectively. The essential oil obtained by hydrodistillation was investigated by GC and GC-MS. The main components of the essential oil were identified to be $(R)$-carvone $(37.98 \%)$ and D-limonene (26.55\%) followed by $\alpha$-pinene (5.21), cis-carveol (5.01\%) and $\beta$-myrcene (4.67\%). (R)Carvone and D-limonene were separated and purified by silica gel column chromatography and preparative thin layer chromatography, and further identified by means of physicochemical and spectrometric analysis. $(R)$-Carvone and D-limonene showed strong contact toxicity against $S$. zeamais $\left(\mathrm{LD}_{50}=2.79\right.$ and $29.86 \mu \mathrm{g} /$ adult $)$ and $T$. castaneum $\left(\mathrm{LD}_{50}=2.64\right.$ and $20.14 \mu \mathrm{g} /$ adult $)$. $(R)$-Carvone and D-limonene also possessed strong fumigant toxicity against $S$. zeamais $\left(\mathrm{LC}_{50}=2.76\right.$ and $\left.48.18 \mathrm{mg} / \mathrm{L}\right)$ and $T$. castaneum adults $\left(\mathrm{LC}_{50}=1.96\right.$ and $\left.19.10 \mathrm{mg} / \mathrm{L}\right)$.
\end{abstract}


Keywords: Carum carvi; Sitophilus zeamais; Tribolium castaneum; fumigant; contact toxicity; essential oil; $(R)$-carvone; D-limonene

\section{Introduction}

During our screening program for new agrochemicals from local wild plants and Chinese medicinal herbs, the essential oil from Carum carvi fruits (Family: Apiaceae) was found to possess insecticidal activity towards the maize weevil, Sitophilus zeamais (Motsch) and red flour beetle, Tribolium castaneum Herbst. Common caraway (C. carvi), one of the oldest herbs known and with a pleasant aroma, is native to Asia, Europe, and North Africa. Its fruits are used in pharmacy, perfumery and food. The dried ripe fruits of C. carvi are used in traditional Chinese medicine and other folk medicines as a carminative, since it is effective against spasmodic gastrointestinal complaints, flatulence, irritable stomach, indigestion, lack of appetite, and dyspepsia in adults [1]. The chemical composition of the essential oil of $C$. carvi collected from various countries has been widely studied [2-6] and great variations in essential oil content and chemical composition of the essential oil were observed. Many data indicated the essential oil possessed antimicrobial, antifungal, molluscidal, nematicidal, antioxidant and antiaflatoxigenic activities, as well as potential as a cancer preventing agent [3, 6-11]. The essential oil of $C$. carvi has been demonstrated to possess strong contact and fumigant toxicity as well as repellency against several insects and mites, e.g. Japanese termite (Reticulitermes speratus) [12], rice weevil (S. oryzae) [13], sciarid fly Lycoriella ingenua larvae [14], the two-spotted spider mite Tetranychus urticae and its predator Phytoseiulus persimilis [15], and the poultry red mite Dermanyssus gallinae [16]. However, no reports on insecticidal activity of essential oil of C. carvi fruits collected from China against stored product insects exist. In this paper, we report the contact and fumigant toxicities of the crude essential oil and two main components derived from the essential oil against two species of grain storage insects.

\section{Results and Discussion}

\subsection{Chemical Composition of the Essential Oils}

The chemical composition of the essential oil derived from C. carvi fruits collected from China was shown in Table 1. The main constituents of $C$. carvi essential oil were $(R)$-carvone $(37.98 \%)$ and D-limonene (26.55\%) followed by $\alpha$-pinene (5.21), cis-carveol $(5.01 \%)$ and $\beta$-myrcene (4.67\%). A total of 30 components were identified in the oil, accounting for $97.58 \%$ of the total oil (Table 1).

The results were different from previous reports. For example, an essential oil of $C$. carvi collected in Qinghai, China contained $(R)$-carvone (51.62\%) and D-limonene (38.26\%) as its two main components [17]. $(R)$-carvone and D-limonene were also found to be the two main constituents in the essential oils collected from Europe and North America [2,5-8]. However, according to some reports these two compounds were not detected in the essential oil of C. carvi. For example, caraway essential oil cultivated in Iran contained $\gamma$-terpinene (24.40\%), 2-methyl-3-phenylpropanal (13.20\%) and 2,4(10)-thujadiene (14.02\%) as its main constituents [24] while in another report on the essential oil of C. carvi from Iran [3] cuminaldehyde $(22.08 \%)$ and $\gamma$-terpinene $(17.86 \%)$ were the two main 
constituents, followed by p-cymene (7.99\%). The main components of the essential oil of C. carvi seeds from Bangladesh were thymol (48.20\%), o-cymene (19.29\%), $\gamma$-terpinene (17.61\%) and trimethylene dichloride (8.81\%) [23]. The above findings suggest that further studies on plant cultivation and essential oil standardization are needed because the chemical composition of the essential oil varies greatly with the plant population.

Table 1. Chemical composition of the essential oil of Carum carvi fruits.

\begin{tabular}{|c|c|c|}
\hline Compounds & RI * & Relative content $(\%)$ \\
\hline$\alpha$-Pinene & 939 & 5.17 \\
\hline$\beta$-Pinene & 974 & 0.02 \\
\hline$\beta$-Myrcene & 991 & 4.67 \\
\hline$p$-Cymene & 1026 & 0.34 \\
\hline D-Limonene & 1029 & 26.55 \\
\hline 1,8-Cineol & 1032 & 0.45 \\
\hline Linalool & 1097 & 0.87 \\
\hline cis-Limonene oxide & 1132 & 0.63 \\
\hline Menthone & 1152 & 0.59 \\
\hline Menthol & 1172 & 0.07 \\
\hline 4-Terpineol & 1174 & 1.34 \\
\hline$\gamma$-Terpinene & 1179 & 0.17 \\
\hline p-Cymen-8-ol & 1182 & 0.49 \\
\hline Dihydrocarvone & 1200 & 1.21 \\
\hline cis-Carveol & 1226 & 5.01 \\
\hline Cuminic aldehyde & 1236 & 0.06 \\
\hline$(R)$-Carvone & 1242 & 37.98 \\
\hline Dihydrocarveol & 1253 & 1.08 \\
\hline$\alpha$-Terpinene-7-al & 1277 & 1.04 \\
\hline Bornyl acetate & 1285 & 0.94 \\
\hline Cumin alcohol & 1288 & 0.72 \\
\hline Eugenol & 1356 & 1.45 \\
\hline Methyleugenol & 1401 & 0.93 \\
\hline Germacrene D & 1479 & 2.81 \\
\hline Myristicin & 1513 & 0.05 \\
\hline Elemicine & 1554 & 0.19 \\
\hline Caryophyllene oxide & 1583 & 1.23 \\
\hline Apiol & 1682 & 0.41 \\
\hline Phytol & 2119 & 0.06 \\
\hline \multicolumn{3}{|l|}{$1,2-$} \\
\hline $\begin{array}{l}\text { Benzenedicarboxylic } \\
\text { acid, mono(2- } \\
\text { ethylhexyl)ester }\end{array}$ & 2549 & 1.05 \\
\hline Total & & 97.58 \\
\hline
\end{tabular}

* RI, retention index as determined on a HP-5MS column using the homologous series of $n$-hydrocarbons as reference. 
$(R)$-Carvone and D-limonene were further separated and purified by silica gel column chromatography and preparative thin layer chromatography based on bioassay-guided fractionation and were characterized from their ${ }^{1} \mathrm{H}-,{ }^{13} \mathrm{C}-\mathrm{NMR}$ and mass spectra. After comparing the physicochemical and spectrometric data with those reported in the literature [20-22], the identities of the two compounds were further confirmed.

\subsection{Insecticidal Activity}

The essential oil of $C$. carvi showed strong contact toxicity against $S$. zeamais and $T$. castaneum adults with $\mathrm{LD}_{50}$ values of 3.07 and $3.39 \mu \mathrm{g}$ /adult, respectively (Table 2). Compared with the famous botanical insecticide, pyrethrum extract (25\% pyrethrine I and pyrethrine II), the essential oil was nine times less active against $T$. castaneum adults because pyrethrum extract displayed a $\mathrm{LD}_{50}$ value of $0.36 \mu \mathrm{g} /$ adult (Table 2). However, it exhibited the same contact toxicity against $S$. zeamais (pyrethrum extract, $\mathrm{LD}_{50}=4.29 \mu \mathrm{g} /$ adult $)$.

Table 3. Contact toxicity of essential oil of Carum carvi and its main components $(R)$-carvone and D-limonene against Sitophilus zeamais (SZ) and Tribolium castaneum (TC) adults.

\begin{tabular}{|c|c|c|c|c|c|c|}
\hline Insect & Compounds & $\begin{array}{c}\mathrm{LD}_{50}{ }^{*} \\
(95 \% \text { FL) }\end{array}$ & $\begin{array}{c}\mathrm{LD}_{90}{ }^{*} \\
(95 \% \mathrm{FL})\end{array}$ & Slope \pm SE & $\begin{array}{c}\text { Chi square } \\
\left(\chi^{2}\right)\end{array}$ & df \\
\hline \multirow[t]{3}{*}{ SZ } & Essential oil & $\begin{array}{c}3.07 \\
(2.89-3.29)\end{array}$ & $\begin{array}{c}4.34 \\
(3.91-4.67)\end{array}$ & $8.52 \pm 1.02$ & 9.36 & 24 \\
\hline & (R)-Carvone & $\begin{array}{c}2.79 \\
(2.53-3.06)\end{array}$ & $\begin{array}{c}3.93 \\
(3.67-4.05)\end{array}$ & $8.66 \pm 0.94$ & 7.44 & 24 \\
\hline & D-Limonene & $\begin{array}{c}29.86 \\
(27.28-30.10)\end{array}$ & $\begin{array}{c}44.86 \\
(41.49- \\
47.23)\end{array}$ & $7.38 \pm 0.84$ & 8.64 & 24 \\
\hline \multirow{5}{*}{$\mathrm{TC}$} & Pyrethrum extract** & $4.29(3.86-4.72)$ & - & - & - & - \\
\hline & Essential oil & $\begin{array}{c}3.39 \\
(3.11-3.72)\end{array}$ & $\begin{array}{c}6.08 \\
(5.57-6.54)\end{array}$ & $5.06 \pm 0.63$ & 12.48 & 24 \\
\hline & (R)-Carvone & $\begin{array}{c}2.64 \\
(2.41-2.93)\end{array}$ & $\begin{array}{c}4.27 \\
(3.91-4.56)\end{array}$ & $6.14 \pm 0.88$ & 6.27 & 24 \\
\hline & D-Limonene & $\begin{array}{c}20.14 \\
(18.45-21.89)\end{array}$ & $\begin{array}{c}43.58 \\
(39.85- \\
46.91)\end{array}$ & $1.59 \pm 0.22$ & 16.02 & 24 \\
\hline & Pyrethrum extract** & $0.36(0.32-0.41)$ & - & - & - & - \\
\hline
\end{tabular}

* Concentration $(\mu \mathrm{g} / \mathrm{adult}) * *$ data from Liu et al. [23].

The essential oil of C. carvi fruits also possessed strong fumigant activity against S. zeamais and $T$. castaneum adults with $\mathrm{LC}_{50}$ values of 3.37 and $2.53 \mathrm{mg} / \mathrm{L}$, respectively (Table 3 ). The currently used grain fumigant, methyl bromide (MeBr) was reported to have fumigant activity against $S$. zeamais and $T$. castaneum adults with $\mathrm{LC}_{50}$ values of 0.67 and $1.75 \mathrm{mg} / \mathrm{L}$, respectively, thus the essential oil was five times less toxic to $S$. zeamais adults compared with the commercial fumigant $\mathrm{MeBr}$. However, the essential oil exhibited the same fumigant toxicity to T. castaneum adults as MeBr. Compared with the other essential oils in the lieterature, the essential oil of $C$. carvi possessed stronger fumigant toxicity 
against T. castaneum adults, e.g. essential oils of Murraya exotica $\left(\mathrm{LC}_{50}=6.84 \mathrm{mg} / \mathrm{L}\right)$ [38], Mentha microphylla $\left(\mathrm{LC}_{50}=4.51 \mu \mathrm{L} / \mathrm{L}\right)$, Citrus reticulata $\left(\mathrm{LC}_{50}=19.47 \mu \mathrm{L} / \mathrm{L}\right)$, Schinus terebenthifolius $\left(\mathrm{LC}_{50}=20.50 \mu \mathrm{L} / \mathrm{L}\right)[39]$, Perovskia abrotanoides $\left(\mathrm{LC}_{50}=11.39 \mu \mathrm{L} / \mathrm{L}\right)[40]$ and Drimys winteri $\left(\mathrm{LC}_{50}=9.0-10.5 \mu \mathrm{L} / \mathrm{L}\right)[41]$, but lesser toxic than the essential oil of Laurelia sempervirens $\left(\mathrm{LC}_{50}=\right.$ 1.6-1.7 $\mu \mathrm{L} / \mathrm{L}$ ) [41]. However, compared with the other essential oils in the previous studies, the essential oil of $C$. carvi exhibited stronger fumigant toxicity against the maize weevils, e.g. essentail oils of $M$. exotica $\left(\mathrm{LC}_{50}=8.29 \mathrm{mg} / \mathrm{L}\right)$ [38], Artemisia lavandulaefolia $\left(\mathrm{LC}_{50}=11.2 \mathrm{mg} / \mathrm{L}\right)$ [24], A. vestita $\left(\mathrm{LC}_{50}=13.42 \mathrm{mg} / \mathrm{L}\right)$ [42], Illicium simonsii $\left(\mathrm{LC}_{50}=14.95 \mathrm{mg} / \mathrm{L}\right)$ [43] and A. sieversiana $\left(\mathrm{LC}_{50}\right.$ $=15.0 \mathrm{mg} / \mathrm{L})$. The above findings suggest that the essential oil of $C$. carvi fruits show potential for development as a novel natural fumigant for stored products.

Table 2. Fumigant toxicity of essential oil of Carum carvi and its main components $(R)$-carvone and D-limonene against Sitophilus zeamais (SZ) and Tribolium castaneum (TC) adults.

\begin{tabular}{|c|c|c|c|c|c|c|}
\hline Insect & Compounds & $\begin{array}{c}\mathbf{L C}_{50} * \\
(95 \% \text { FL) }\end{array}$ & $\begin{array}{c}\mathbf{L C}_{90} * \\
(95 \% \text { FL) }\end{array}$ & Slope \pm SE & Chi square $\left(\chi^{2}\right)$ & df \\
\hline \multirow{6}{*}{$\mathrm{SZ}$} & Essential oil & 3.37 & 5.04 & $7.34 \pm 0.84$ & 6.48 & 24 \\
\hline & & $(3.02-3.73)$ & $(4.69-5.43)$ & & & \\
\hline & (R)-Carvone & 2.76 & 4.56 & $5.89 \pm 0.56$ & 14.40 & 24 \\
\hline & & $(2.59-2.92)$ & $(4.23-4.89)$ & & & \\
\hline & D-Limonene & 48.18 & 104.24 & $3.74 \pm 0.40$ & 14.88 & 24 \\
\hline & & $(45.29-51.04)$ & $(96.46-108.95)$ & & & \\
\hline \multirow{8}{*}{$\mathrm{TC}$} & $\mathrm{MeBr}^{* *}$ & 0.67 & - & - & - & - \\
\hline & Essential oil & 2.53 & 5.47 & $3.83 \pm 0.43$ & 8.40 & 24 \\
\hline & & $(2.38-2.68)$ & $(4.97-5.89)$ & & & \\
\hline & (R)-Carvone & 1.96 & 3.67 & $4.65 \pm 0.59$ & 6.96 & 24 \\
\hline & & $(1.83-2.12)$ & $(3.41-3.93)$ & & & \\
\hline & D-Limonene & 19.10 & 29.19 & $7.25 \pm 0.89$ & 15.84 & 24 \\
\hline & & $(17.53-20.04)$ & $(27.22-31.57)$ & & & \\
\hline & $\mathrm{MeBr}^{* *}$ & 1.75 & - & & - & - \\
\hline
\end{tabular}

The isolated compound, $(R)$-carvone showed stronger contact toxicity against S. zeamais and $T$. castaneum adults ( $\mathrm{LD}_{50}=2.79$ and $2.64 \mu \mathrm{g}$ /adult, respectively) than the other isolated compound, Dlimonene $\left(\mathrm{LD}_{50}=29.86\right.$ and $20.14 \mu \mathrm{g}$ /adult, respectively) (Table 2). Moreover, $(R)$-carvone also possessed stronger fumigant toxicity against $S$. zeamais and $T$. castaneum adults $\left(\mathrm{LC}_{50}=2.76\right.$ and $1.96 \mathrm{mg} / \mathrm{L}$ air, respectively) than D-limonene $\left(\mathrm{LD}_{50}=48.18\right.$ and $19.10 \mathrm{mg} / \mathrm{L}$ air, respectively) (Table 3). Compared with the commercial fumigant $\mathrm{MeBr},(R)$-carvone exhibited the same fumigant toxicity against $T$. castaneum adults although four times less toxic to $S$. zeamais adults.

In previous reports, $(R)$-carvone has been demonstrated to possess insecticidal activity against several species of insects and mites, e.g. Japanese termite (R. speratus) [12], sciarid fly (L. ingenua) [13], several stored product insects, rice weevil (S. oryzae), lesser grain borer (R. dominica), red flour beetle (T. castaneum) and flat grain beetle (Cryptolestes pusillus) [26-29], German cockroaches (Blattella germanica) [30] and the two-spotted spider mite, T. urticae [31]. D-Limonene has been 
commercialized for use as flea dips and shampoos for pets as well as sprays and aerosols [32]. It has been demonstrated to possess insecticidal activity against several stored-product insects such as the cowpea weevil (C. maculates), lesser grain borer ( $R$. dominica), flat grain beetle (C. pusillus), rice weevil (S. oryzae), maize weevil (S. zeamais) and red flour beetle (T. castaneum) [28, 29, 33-35] as well as against the stored food mite Tyrophagus putrescentiae [36]. The two compounds were demonstrated to be a potent inhibitor of acetylcholinesterase (AChE) activity from larvae of several stored product insects [27, 29].

Considering the currently used fumigants are synthetic insecticides, fumigant activity of the crude essential oil and the two isolated compounds are quite promising and they show potential for development as possible natural fumigants for the control of stored product insects. However, for the practical application of the essential oil/compounds as novel fumigants, further studies on the safety of the essential oil/compounds to humans and on development of formulations are necessary to improve the efficacy and stability and to reduce cost.

\section{Experimental}

\subsection{General}

${ }^{1} \mathrm{H}$ and ${ }^{13} \mathrm{C}$ NMR spectra were recorded on Bruker Avance DRX 500 instruments using $\mathrm{CDCl} 3$ as solvent with TMS as internal standard. EIMS were determined on a ThermoQuest Trace 2000 mass spectrometer at $70 \mathrm{eV}$ (probe). Silica gel (160-200 mesh) and pre-coated GF254 plates were purchased from Qingdao Marine Chemical Plant (Shandong Province, China). Fluon was purchased from ICI America Inc (USA). $\mathrm{C}_{8}-\mathrm{C}_{24} n$-alkanes were purchased from Sigma-Aldrich (USA). All other unlabelled chemicals and reagents were of analytical grade.

\subsection{Plant material}

Fruits ( $1 \mathrm{~kg}$ ) of C. carvi were purchased from Qinghai Chinese Medicinal Herbs Company, Qinghai Province, Xining 810000, China. The voucher specimen (BNU-CMH-Dushuahan-2009-08-25-006) was deposited at the Herbarium (BNU) of College of Life Sciences, Beijing Normal University. The fruits were air-dried for one week and ground to a powder for use.

\subsection{Insects}

The maize weevils (S. zeamais) and red flour beetles ( $T$. castaneum) were obtained from laboratory cultures maintained in the dark in incubators at $29-30{ }^{\circ} \mathrm{C}$ and $70-80 \%$ r.h. The red flour beetles were reared on wheat flour mixed with yeast $(10: 1, \mathrm{w} / \mathrm{w})$ while maize weevils were reared on whole wheat at $12-13 \%$ moisture content. Unsexed adult weevils/beetles used in all the experiments were about 2 weeks old.

\subsection{Essential Oil Distillation}

The ground powder of $C$. carvi fruits was subjected to hydrodistillation using a modified Clevengertype apparatus for $6 \mathrm{~h}$. Anhydrous sodium sulphate was used to remove water after extraction. Essential oils were stored in airtight containers in a refrigerator at $4{ }^{\circ} \mathrm{C}$. The oil yields were $6.58 \% \mathrm{v} / \mathrm{w}$. 


\subsection{Purification and Characterization of D-Limonene and (R)-Carvone}

The crude essential oil was chromatographed on a silica gel column by gradient elution with $n$-hexane first, then with $n$-hexane-ethyl acetate, and last with acetone to obtain 25 fractions. Of these, fraction 6 and 9 were further separated by PTLC with petroleum ether-acetone $(50: 1, \mathrm{v} / \mathrm{v})$ to afford two pure compounds, respectively.

D-Limonene (1). Colorless oil. ${ }^{1} \mathrm{H}-\mathrm{NMR}\left(\mathrm{CDCl}_{3}, 500 \mathrm{MHz}\right) \delta(\mathrm{ppm}): 1.78\left(3 \mathrm{H}, \mathrm{m}, 10-\mathrm{CH}_{3}\right), 1.82(3 \mathrm{H}$, m, 7-CH $\left.\mathrm{CH}_{3}\right), 2.11(1 \mathrm{H}, \mathrm{m}, \mathrm{H}-5), 2.39(1 \mathrm{H}, \mathrm{m}, \mathrm{H}-3), 2.45$ (1H, m, H-5), 2.57 (1H, s, H-3), 2.69 (1H, s, H-4), 4.76(1H, s, H-9), 4.81(1H, s, H-9), $7.65(1 \mathrm{H}, \mathrm{s}, \mathrm{H}-6) ;{ }^{13} \mathrm{C}-\mathrm{NMR}\left(\mathrm{CDCl}_{3}, 125 \mathrm{MHz}\right) \delta(\mathrm{ppm}): 199.34$ (C-2), 146.69 (C-8), 144.40 (C-6), 135.45 (C-1), 110.47 (C-9), 43.20 (C-3), 42.55 (C-4), 31.30 (C-5), 20.50 (C-10), 15.63 (C-7). Its identity was confirmed by the ESI-MS with the mass spectral fragmentation pattern $[\mathrm{m} / \mathrm{z}$ (\% abundance): 150(6.5), 108(31.9), 107(16.8), 106(11.4), 93(26.5), 82(100), 79(10.8), 54(47.6), 53(13.4), 41(18.5), 39(24.9), 27 (11.3)].

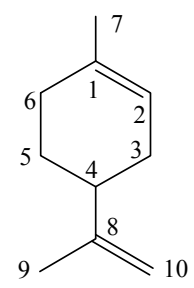

(D)-Limonene

(R)-Carvone (2). Colorless oil. ${ }^{1} \mathrm{H}-\mathrm{NMR}\left(\mathrm{CDCl}_{3}, 500 \mathrm{MHz}\right) \delta(\mathrm{ppm}): 1.47(1 \mathrm{H}, \mathrm{m}, \mathrm{H}-5), 1.65(3 \mathrm{H}, \mathrm{s}$, 7- $\left.\mathrm{CH}_{3}\right), 1.73\left(3 \mathrm{H}, \mathrm{s}, 9-\mathrm{CH}_{3}\right), 1.79$ (1H, m, H-5), 1.89 (1H, m, H-6), 1.97 (2H, m, H-3), 2.05 (1H, m, H-6), $2.08(1 \mathrm{H}, \mathrm{m}, \mathrm{H}-4), 4.70(2 \mathrm{H}, \mathrm{s}, \mathrm{H}-10), 5.40(1 \mathrm{H}, \mathrm{s}, \mathrm{H}-2) .{ }^{13} \mathrm{C}-\mathrm{NMR}\left(\mathrm{CDCl}_{3}, 125 \mathrm{MHz}\right) \delta(\mathrm{ppm})$ : 150.14 (C-8), 133.66 (C-1), 120.78 (C-2), 108.48 (C-10), 41.23 (C-4), 30.94 (C-6), 30.71 (C-3), 28.06 (C-5), 3.48 (C-7), 20.82 (C-9). Its identity was confirmed by the ESI-MS with the mass spectral fragmentation pattern $[\mathrm{m} / \mathrm{z}$ (\% abundance): 136 (22.6), 121 (19.5), 107 (17.1), 94 (22.6), 93 (59.1), 92 (18.8), 91 (12.7), 81 (10.9), 80 (11.1), 79 (22.8), 77 (11.7), 68 (100.0), 67 (44.7) 53 (17.1), 41 (19.3), 39 (15.6), $27(10.3)]$.

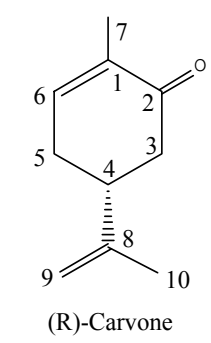

\subsection{Gas Chromatography and Mass Spectrometry}

Gas chromatographic analysis was performed on an Agilent $6890 \mathrm{~N}$ instrument equipped with a flame ionization detector and HP-5MS $(30 \mathrm{~m} \times 0.25 \mathrm{~mm} \times 0.25 \mu \mathrm{m})$ capillary column, while the essential oil components were identified on an Agilent Technologies 5973N mass spectrometer. The GC settings were as follows: the initial oven temperature was held at $60{ }^{\circ} \mathrm{C}$ for $1 \mathrm{~min}$ and ramped at $10{ }^{\circ} \mathrm{C} \mathrm{min}{ }^{-1}$ to $180{ }^{\circ} \mathrm{C}$ for $1 \mathrm{~min}$, and then ramped at $20^{\circ} \mathrm{C} \mathrm{min}-1$ to $280{ }^{\circ} \mathrm{C}$ for $15 \mathrm{~min}$. The injector 
temperature was maintained at $270{ }^{\circ} \mathrm{C}$. The samples $(1 \mu \mathrm{L})$ were injected neat, with a split ratio of 1:10. The carrier gas was helium at flow rate of $1.0 \mathrm{~mL} \mathrm{~min}^{-1}$. Spectra were scanned from 20 to $550 \mathrm{~m} / \mathrm{z}$ at 2 scans $\mathrm{s}^{-1}$. Most constituents were identified by gas chromatography by comparison of their retention indices with those of the literature or with those of authentic compounds available in our laboratories. The retention indices were determined in relation to a homologous series of $n$-alkanes $\left(C_{8}-C_{24}\right)$ under the same operating conditions. Further identification was made by comparison of their mass spectra with those stored in NIST 05 and Wiley 275 libraries or with mass spectra from literature [4-6,18]. Component relative percentages were calculated based on GC peak areas without using correction factors.

\subsection{Fumigant Toxicity}

The fumigant activity of the essential oil and the pure compounds against S. zeamais and T. castaneum adults was tested as described by Liu and Ho [37]. Range-finding studies were run to determine the appropriate testing concentrations. A serial dilution of the essential oil/compound (0.05\%-3.0\% for pure compounds, $0.30-5.40 \%$ for oil, five concentrations) was prepared in $n$-hexane. A Whatman filter paper (diameter $2.0 \mathrm{~cm}$ ) were each impregnated with $10 \mu \mathrm{L}$ dilution, and then placed on the underside of the screw cap of a glass vial (diameter $2.5 \mathrm{~cm}$, height $5.5 \mathrm{~cm}$, volume $25 \mathrm{~mL}$ ). The solvent was allowed to evaporate for $15 \mathrm{~s}$ before the cap was placed tightly on the glass vial, each of which contained 10 insects inside to form a sealed chamber. Fluon (ICI America Inc) was used inside glass vial to prevent insects from contacting the treated filter paper. Preliminary experiments demonstrated that $15 \mathrm{~s}$ was sufficient for the evaporation of solvents. $n$-Hexane was used as a control. Five replicates were carried out for all treatments and controls, and they were incubated for $24 \mathrm{~h}$. The insects were then transferred to clean vials with some culture media and returned to the incubator and observed daily for determination of end-point mortality, which was reached after one week. The experiments were repeated in three times. The $\mathrm{LC}_{50}$ values were calculated by using Probit analysis [19].

\subsection{Contact Toxicity}

The contact toxicity of the essential oil/pure compounds against $S$. zeamais and T. castaneum adults was measured as described by Liu and Ho [37]. Range-finding studies were run to determine the appropriate testing concentrations. A serial dilution of the two essential oils $(1.20 \%-5.0 \%$ for pure compounds, $1.50-5.20 \%$ for oil, five concentrations) was prepared in $n$-hexane. Aliquots of $0.5 \mu \mathrm{L}$ of the dilutions were applied topically to the dorsal thorax of the insects. Controls were determined using $n$-hexane. Five replicates were carried out for all treatments and controls. Both treated and control insects were then transferred to glass vials (10 insects/vial) with culture media and kept in incubators. Mortality of insects was observed daily until end-point mortality was reached one week after treatment. The experiments were repeated in three times. The $\mathrm{LD}_{50}$ values were calculated by using Probit analysis [19].

\section{Conclusions}

Identified through mass screening, essential oil of $C$. carvi fruits and its major components were examined for insecticidal activity against the maize weevils and red flour beetles. The essential oil 
possessed strong fumigant toxicity against $S$. zeamais adults, although it was five times less toxic compared to the commercial fumigant $\mathrm{MeBr}$. However, the essential oil exhibited the same fumigant toxicity to $T$. castaneum adults as $\mathrm{MeBr}$. The two isolated compounds also exhibited strong fumigant toxicity against $S$. zeamais and T. castaneum adults. The essential oil and the two compounds also showed contact toxicity against the two species of grain storage insects. These findings, considered together, suggest that the essential oil and the two compounds show potential for development as natural fumigants for stored products.

\section{Acknowledgements}

This work was funded by the Hi-Tech Research and Development of China 2011AA10A202 and National New-drug Innovation Project 2009ZX09501-014. The authors thank Liu Q.R. from College of Life Sciences, Beijing Normal University, Beijing 100875, for the identification of the investigated medicinal herb.

\section{References and Notes}

1. Jiangsu New Medical College. Dictionary of Chinese Herbal Medicine; Shanghai Science \& Technology Press: Shanghai, China, 1977; pp. 2673.

2. Kallio, H.; Kerrola, K.; Alhonmaki, P. Carvone and limonene in caraway fruits (Carum carvi L.) analyzed by supercritical carbon dioxide extraction-gas chromatography. J. Agric. Food Chem. 1994, 42, 2478-2485.

3. Razzaghi-Abyaneh, M.; Shams-Ghahfarokhi, M.; Rezaee, M.B.; Jaimand, K.; Alinezhad, S.; Saberi, R.; Yoshinari, T. Chemical composition and antiaflatoxigenic activity of Carum carvi L., Thymus vulgaris and Citrus aurantifolia essential oils. Food Control 2009, 20, 1018-1024.

4. Laribi, B.; Kouki, K.; Mougou, A.; Marzouk, B. Fatty acid and essential oil composition of 3 Tunisian caraway (Carum carvi L.) seed ecotypes. J. Sci. Food Agric. 2010, 90, 391-396.

5. Seidler-Lozykowska, K.; Baranska, M.; Baranski, R.; Krol, D. Raman analysis of caraway (Carum carvi L.) single fruits. Evaluation of essential oil content and its composition. J. Agric. Food Chem. 2010, 58, 5271-5275.

6. Samojlik, I.; Lakic, N.; Mimica-Dukic, N.; Dakovic-Svajcer, K.; Bozin, B. Antioxidant and hepatoprotective potential of essential oils of coriander (Coriandrum sativum L.) and caraway (Carum carvi L.) (Apiaceae). J. Agric. Food Chem. 2010, 58, 8848-8853.

7. Simic, A.; Rancic, A.; Sokovic, M. D.; Ristic, M.; Grujic-Jovanovic, S.; Vukojevic, J.; Marin, P. D. Essential oil composition of Cymbopogon winterianus and Carum carvi and their antimicrobial activities. Pharm. Biol. (NY, USA) 2008, 46, 437-441.

8. Iacobellis, N.S.; Lo Cantore, P.; Capasso, F.; Senatore, F. Antibacterial activity of Cuminum cyminum L. and Carum carvi L. essential oils. J. Agric. Food Chem. 2005, 53, 57-61.

9. Oka, Y.; Nacar, S.; Putievsky, E.; Ravid, U.; Yaniv, Z.; Spiegel, Y. Nematicidal activity of essential oils and their components against the root-knot nematode. Phytopathology 2000, 90, $710-715$. 
10. Kumar, P.; Singh, D.K. Molluscicidal activity of Ferula asafoetida, Syzygium aromaticum and Carum carvi and their active components against the snail Lymnaea acuminata. Chemosphere 2006, 63, 1568-1574.

11. Zheng, G.; Kenney, P.M.; Lam, L.K.T. Anethofuran, carvone, and limonene: potential cancer chemopreventive agents from dill weed oil and caraway oil. Planta Med. 1992, 58, 338-341.

12. Seo, S.M.; Kim, J.; Lee, S.G.; Shin, C.H.; Shin, S.C.; Park, I.K. Fumigant antitermitic activity of plant essential oils and components from ajowan (Trachyspermum ammi), allspice (Pimenta dioica), caraway (Carum carvi), dill (Anethum graveolens), geranium (Pelargonium graveolens), and litsea (Litsea cubeba) oils against Japanese termite (Reticulitermes speratus Kolbe). J. Agric. Food Chem. 2009, 57, 6596-6602.

12. Yoon, C.; Kang, S.H; Jang, S.A.; Kim, Y.J.; Kim, G.H. Repellent efficacy of caraway and grapefruit oils for Sitophilus oryzae (Coleoptera: Curculionidae). J. Asia-Pacific Entomol. 2007, 10, 263-267.

13. Park, I.K.; Kim, J.N.; Lee, Y.S.; Lee, S.G.; Ahn, Y.J.; Shin, S.C. Toxicity of plant essential oils and their components against Lycoriella ingenua (Diptera: Sciaridae). J. Econ. Entomol. 2008, 101, 139-144.

14. Choi, W.I.; Lee, S.G.; Park, H.M.; Ahn, Y.J. Toxicity of plant essential oils to Tetranychus urticae (Acari: Tetranychidae) and Phytoseiulus persimilis (Acari: Phytoseiidae). J. Econ. Entomol. 2004, 97, 553-558.

15. George, D.R.; Sparagano, O.A.E.; Port, G.; Okello, E.; Shiel, R.S.; Guy, J.H. Repellence of plant essential oils to Dermanyssus gallinae and toxicity to the non-target invertebrate Tenebrio molitor. Vet. Parasitol. 2009, 162, 129-134.

16. Tan, R.; Wang, B.; Chen, S.L. GC-MS analysis of Carum carvi essential oil. J. Chin. Med. Materials 2003, 26, 869-870.

17. Adams, R.P. Identification of Essential Oil Components by Gas Chromatography/Quadrupole Mass Spectroscopy; Allured: Carol Stream, IL, USA, 2001.

18. Sakuma, M. Probit analysis of preference data. Appl. Entomol. Zool. 1998, 33, 339-347.

19. Bohlmann, F.; Zeisberg, R.; Klein, E. Naturally occurring terpene derivatives. Carbon-13 NMR spectra of monoterpenes. Org. Magn. Reson. 1975, 7, 426-432.

20. Talzi, V.P. A ${ }^{13} \mathrm{C}$ and ${ }^{1} \mathrm{H}$ NMR analysis of perfumes. Russian J. Appl. Chem. 2006, 79, 107-116.

21. Meschler, J.P.; Howlett, A.C. Thujone exhibits low affinity for cannabinoid receptors but fails to evoke cannabinimetic responses. Pharmacol. Biochem. Behav. 1999, 62, 473-480.

22. Begum, J.; Bhuiyan, M.N.I.; Chowdhury, J.U.; Hoque, M.N.; Anwar, M.N. Antimicrobial activity of essential oil from seeds of Carum carvi and its composition. Bangladesh J. Microbiol. 2008, 25 , 85-89.

23. Liu, Z.L.; Liu, Q.R.; Chu, S.S.; Jiang, G.H. Insecticidal activity and chemical composition of the essential oils of Artemisia lavandulaefolia and Artemisia sieversiana from China. Chem. Biodiv. 2010, 7, 2040-2045.

24. Jalali-Heravi, M.; Zekavat, N.; Sereshti, H. Use of gas chromatography-mass spectrometry combined with resolution methods to characterize the essential oil components of Iranian cumin and caraway. J. Chromatogr. A 2007, 1143, 215-222. 
25. Lopez, M.D.; Contreras, J.; Pascual-Villalobos, M.J. Selection for tolerance to volatile monoterpenoids in Sitophilus oryzae (L.), Rhyzopertha dominica (F.) and Cryptolestes pusillus (Schoenherr). J. Stored Prod. Res. 2010, 46, 52-58.

26. Lopez, M.D.; Pascual-Villalobos, M.J. Mode of inhibition of acetylcholinesterase by monoterpenoids and implications for pest control. Ind. Crop Prod. 2010, 31, 284-288.

27. Badawy, M.E.I.; El-Arami, S.A.A.; Abdelgaleil, S.A.M. Acaricidal and quantitative structure activity relationship of monoterpenes against the two-spotted spider mite, Tetranychus urticae. Exp. Appl. Acarol. 2010, 52, 261-274.

28. Abdelgaleil, S.A.M.; Mohamed, M.I.E.; Badawy, M.E.I.; El-Arami, S.A.A. Fumigant and contact toxicities of monoterpenes to Sitophilus oryzae (L.) and Tribolium castaneum (Herbst) and their inhibitory effects on acetylcholinesterase activity. J. Chem. Ecol. 2009, 35, 518-525.

29. Jang, Y.S.; Yang, Y.C.; Choi, D.S.; Ahn, Y.J. Vapor phase toxicity of marjoram oil compounds and their related monoterpenoids to Blattella germanica (Orthoptera: Blattellidae). J. Agric. Food Chem. 2005, 53, 7892-7898.

30. Lopez, M.D.; Jordan, M.J.; Pascual-Villalobos, M.J. Toxic compounds in essential oils of coriander, caraway and basil active against stored rice pests. J. Stored Prod. Res. 2008, 44, 273-278.

31. Ibrahim, M.A.; Kainulainen, P.; Aflatuni, A.; Tiilikkala, K.; Holopainen, J. Insecticidal, repellent, antimicrobial activity and phytotoxicity of essential oils: with special reference to limonene and its suitability for control of insect pests. Agric. Food Sci. Finland 2001, 10, 245-261.

32. Prates, H.T.; Santos, J.P.; Waquil, J.M.; Fabris, J.D.; Oliveira, A.B.; Foster, J.E. Insecticidal activity of monoterpenes against Rhyzopertha dominica (F.) and Tribolium castaneum (Herbst). J. Stored Prod. Res. 1988, 34, 243-249.

33. Bekele, A.J.; Hassanali, A. Blend effects in the toxicity of the essential oil constituents of Ocimum kilimandscharicum and Ocimum kenyense (Labiateae) on two post-harvest insect pests. Phytochemistry 2001, 57, 385-391.

34. Lee, B.H,; Choi, W,S.; Lee, S.E.; Park, B.S. Fumigant toxicity of essential oils and their constituent compounds towards the rice weevil, Sitophilus oryzae (L.). Crop. Prot. 2001, 20, 317-320.

35. Tripathi, A.K.; Prajapati, V.; Khanuja, S.P.S.; Kumar, S. Effect of D-limonene on three storedproduct beetles. J. Econ. Entomol. 2003, 96, 990-995.

36. Liu, Z.L.; Ho, S.H. Bioactivity of the essential oil extracted from Evodia rutaecarpa Hook f. et Thomas against the grain storage insects, Sitophilus zeamais Motsch. and Tribolium castaneum (Herbst). J. Stored Prod. Res. 1999, 35, 317-328.

37. Li, W.Q.; Jiang, C.H.; Chu, S.S.; Zuo, M.X.; Liu, Z.L. Chemical composition and toxicity against Sitophilus zeamais and Tribolium castaneum of the essential oil of Murraya exotica aerial parts. Molecules 2010, 15, 5831-5839.

38. Mohamed, M.I.; Abdelgaleil, S.A.M. Chemical composition and insecticidal potential of essential oils from Egyptian plants against Sitophilus oryzae (L.) (Coleoptera: Curculionidae) and Tribolium castaneum (Herbst) (Coleoptera: Tenebrionidae). Appl. Entomol. Zool. 2008, 43, 599-607.

39. Arabi, F.; Moharramipour, S.; Sefidkon, F. Chemical composition and insecticidal activity of essential oil from Perovskia abrotanoides (Lamiaceae) against Sitophilus oryzae (Coleoptera: Curculionidae) and Tribolium castaneum (Coleoptera: Tenebrionidae). Int. J. Trop. Insect Sci. 2008, 28, 144-150. 
40. Zapata, N.; Smagghe, G. Repellency and toxicity of essential oils from the leaves and bark of Laurelia sempervirens and Drimys winteri against Tribolium castaneum. Ind. Crop. Prod. 2010, 32, 405-410.

41. Chu, S.S.; Liu, Q.R.; Liu, Z.L. Insecticidal activity and chemical composition of the essential oil of Artemisia vestita from China against Sitophilus zeamais. Biochem. Syst. Ecol. 2010, 38, 489-492.

42. Chu, S.S.; Liu, S.L.; Jiang, G.H.; Liu, Z.L. Composition and toxicity of essential oil of Illicium simonsii Maxim (Illiciaceae) fruit against the maize weevils. Rec. Nat. Prod. 2010, 4, 205-210.

Sample Availability: Samples of the essential oil and pure compounds are available from the authors.

(C) 2010 by the authors; licensee MDPI, Basel, Switzerland. This article is an open access article distributed under the terms and conditions of the Creative Commons Attribution license (http://creativecommons.org/licenses/by/3.0/). 